Meta

Journal des traducteurs

Translators' Journal

\title{
A Description of Various Types of Omissions, Additions and Errors of Translation Encountered in Simultaneous Interpretation
}

\section{Henri C. Barik}

Volume 16, numéro 4, décembre 1971

URI : https://id.erudit.org/iderudit/001972ar

DOI : https://doi.org/10.7202/001972ar

Aller au sommaire du numéro

Éditeur(s)

Les Presses de l'Université de Montréal

ISSN

0026-0452 (imprimé)

1492-1421 (numérique)

Découvrir la revue

Citer cet article

Barik, H. C. (1971). A Description of Various Types of Omissions, Additions and Errors of Translation Encountered in Simultaneous Interpretation. Meta, 16(4), 199-210. https://doi.org/10.7202/001972ar d'utilisation que vous pouvez consulter en ligne. 


\section{a description}

of various types

of omissions, additions

\section{and errors}

\section{of translation}

\section{encountered in simultaneous interpretation*}

In simultaneous interpretation, the interpreter's version may depart from the original version in three general ways : the interpreter (henceforth abbreviated $\mathrm{T}$ for « translator», since it cannot conveniently be abbreviated « $\mathbf{I} »)$ may omit some material uttered by the speaker (abbreviated $\mathrm{S}$ ), he may add some material to the text, or he may substitute material, resulting in his saying not quite the same thing as the $\mathbf{S}$. If the substitution is at considerable variance with the original version, we may speak of an "error $»$ of translation ${ }^{1}$. This paper presents a very general classification or coding scheme developed in relation to these three types of events, along with some relevant data. The work was carried out in the context of an investigation of simultaneous interpretation in which Ts of varying proficiency levels (professional Ts, «student» Ts and « amateurs ») were required to do the simultaneous interpretation of several passages recorded on tape, which represented different types of materials (spontaneous, semi-prepared and fully prepared or «formal » material), the languages involved being English and French ${ }^{2}$. The coding system is necessarily subjective to a large extent since it was developed by one person only (the writer), though in consultation with another qualified person (and there was substantial agreement between the two judges in the codes

* This paper is based on part of an unpublished doctoral dissertation submitted to the Department of Psychology of the University of North Carolina (Chapel Hill). The author is grateful to his thesis advisor, Samuel Fillenbaum, for his guidance. The study was supported by United States Public Health Service Research Grant M-10006 from the National Institute of Mental Health.

1. The terms "translation" and "to translate " are employed regularly in the present paper in the place of "interpretation " and " to interpret ", with the understanding that they refer to « oral " translation, i.e. interpretation, and not to formal or written translation.

2. Henri C. Barik, A Study of Simultaneous Interpretation, unpublished doctorat dissertation, University of North Carolina (Chapel Hill), 1969 (on file with University Microfilms, Ann Arbor, Michigan; Order no. 70-3192). For summary see : Henri C. Barik, "Some Findings on Simultaneous Interpretation ", Proceedings of the 78 th Annual Convention of the American Psychological Association, 1970, V (Pt. 1), p. 11-12; Henri C. Barik, "Interpreters Talk a Lot, among Other Things », Babel, 1972 (in press). 
assigned to a few sample texts). Still, it may be of some value to interpreters and to other researchers interested in the issue.

To arrive at the coding scheme, the recorded materials (there were 48 recordings altogether, each of 6 Ts interpreting 8 passages) were monitored several times and were followed at the same time on transcripts of the texts. The $S$ and $\mathrm{T}$ versions, which were recorded on different tracks of the tape, could be considered either separately or simultaneously. All events judged to represent departures, however slight, of the interpretation from the original were noted and coded, being reported on the $S$ transcript in the case of omissions, on the $T$ transcript in the case of additions, and on both transcripts in the case of substitutions or errors, as shown in the brief example at the end of the present article ${ }^{3}$. The list of departures so produced was reconsidered a number of times, and items relating to the same type of event were combined. From this operation emerged the final coding scheme employed in the study, which we now describe.

\section{CODING SCHEME}

The categories of departures of translation resulting from the coding operation are as follows :

1. Omissions - These, as stated, refer to items present in the original version which are left out of the translation by the $T$. Here we are dealing with clear omissions and not omissions resulting from the substitution of one thing for another by the $\mathrm{T}$; the latter fall under the category of substitutions and errors. Omissions are determined on the basis of the final content of the original message, so that it is not considered an omiss:on if the $\mathrm{T}$ does not translate a lexically irrelevant repetition or «false start» on the part of the S. Four main types of events fall under the heading of omissions (coded $\mathrm{M}$, for « missing » material) :

a) $M 1$ : skipping omission - omission of single word or short phrase by $\mathrm{T}$, who seems to skip over it. This type of omission usually refers to a qualifying adjective or some related event being left out of the translation by the $T$. The omission does not alter the grammatical structure of the sentence and results in very little loss in meaning.

E.g. S version : ... un instrument assez difficile ...

T version : ... a difficult instrument ...

Such skipping omissions are of minor importance, and most of them are probably acceptable within the context of simultaneous interpretation. To these omissions were added some instances of other similar types of events, such as the omission of a preposition or a conjunction due to the restructuring of a sentence, where there is little change in meaning.

E.g. S version : ... les garçons continuaient à grandir jusqu’à 18 ou 20 ans, alors que de nos jours ...

$\mathrm{T}$ version : ... boys continued to grow until 18 or 20 . Nowadays ...

3. Transcripts of the texts employed in the study and of the interpretations obtained (full set of 8 translations for 2 Ts and sample of 3 translations for 4 Ts) have been deposited with the National Auxiliary Publications Service of the American Society for Information Science Inc., c/o CCM Information Sciences Inc., 909 Third Avenue, New York, New York 1022. These transcripts reproduce the texts only; omissions and other departures of translation are not indicated on them. 
b) $M 2$ : comprehension omission - omission where it appears that the $\mathrm{T}$ fails to comprehend or is unable to interpret part of the text. There is thus an interruption in his translation. This type of omission usually involves bigger units of material. The omission results in a definite loss in meaning. It may also result in disjointed speech on the part of the $\mathrm{T}$, consisting of « bits and pieces $»$ of translation.

E.g. S version : ... depuis l'époque où il avait coutume de venir nous voir il $\mathrm{y}$ a des années à la Jamaïque. Je n’ai jamais admiré ou aimé personne plus que lui ...

$T$ version : ... since the time when years ago ... I have never ...

Such omissions are obviously more serious than the first type.

c) $M 3$ : delay omission - As possibly a subcategory of $M 2$, we coded omissions which seemed to be due in large part to the delay of the $T$ in his translation, as judged from listening to the tape. This would happen when, as the $\mathrm{T}$ was giving his translation of a segment of the text, the $\mathrm{S}$ resumed speaking, with the result that some of what $\mathrm{S}$ said did not seem to « register » with the $\mathrm{T}$, who would then either wait until the beginning of a new unit of meaning or else would bypass what had been said in order to «catch up ». Whereas in $M 2$ the $T$ did not seem to comprehend what was said or was unable to convert it into the target language, in the present category the assumption was that, had the $T$ not lagged behind in his translation and had he been able to pay attention to what was being said, he may have been able to translate it. Of course, the $\mathrm{T}$ must necessarily lag slightly behind the $\mathrm{S}$ in his delivery, so that delay is a permanent factor to take into consideration; however, here it appeared to be possibly the primary reason for the omission. There is, however, no hard and fast distinction between omission types $M 2$ and $M 3$, and there was a large subjective element in deciding which category was the more applicable in a particular instance.

d) M4 : compounding omission - In the three types of omissions above, although disjointed speech may have resulted (M2 and M3), the «logic» of the text or the relationship between grammatical units was not altered. In some cases, however, the $\mathrm{T}$ seemed to recombine or compound elements from different clause groupings by omitting some material, with the result that the sentence had a slightly altered meaning, even if the gist of what was said was maintained.

E.g. S version : ... J'étais à Londres mercredi soir lorsque la nouvelle s'est répandue que ...

$\mathrm{T}$ version : ... Wednesday evening the news spread that ...

In this example, the $\mathrm{T}$ version carries the gist of the message but, through omitted material, compounds several units, giving the sentence a different meaning. This is not a case of disjointed material as in previous categories, since the T's delivery is smooth, and it appears that he selectively regrouped material from different constructions, forming a new entity. This type of omission, though not too common, is rather interesting. Such omissions sometimes seem to result from a lengthy delay on the part of the $\mathrm{T}:$ as the $\mathrm{T}$ is translating one segment of text, the $\mathrm{S}$ resumes speaking and it appears that part of what he says fails to register with the $T$, who may combine parts of different segments, if the contents permit it. Although such compounding omissions associated with delay were initially coded separately from those seeming to stem from selective encoding on the part of the $T$, the two instances were subsequently combined in the final coding scheme. 
In addition to the above types of omissions, some other instances of omitted material were also coded at first but were later discarded since they represent inconsequential omissions, some of which, as in ii) below, are even desirable. Among these were the following : $i$ ) omission of connective « and 》 (or French et) between words, phrases or sentences, where its omission is not disruptive; ii) omission of superfluous and often untranslatable material, in the form of «fillers » such as «well», «now», «you see», etc. in English or n'est-ce pas, eh bien, etc. in French. These occurred occasionally in spontaneous and semi-prepared texts; iii) omission of definite articles, etc., which should have been given; $i v$ ) omission of specification, as when, for example, «this young man » is rendered in translation as « the young man », or when a specified item such as « children $»$ is rendered by a corresponding pronoun such as «they », where its reference is understood from the context.

These types of omissions are in fact quite acceptable within the context of simultaneous interpretation. Our concern was more with those departures of the translation from the original which to some degree affect the meaning of what is said. In some instances, such as omission type $M I$, this represents a very minor departure ; in other cases it is more serious.

2. Additions - This category refers to material which is added outright to the text by the $T$. New material introduced by the $T$ on account of an error of translation, even though it represents something which is not in the original, is not considered an addition but falls instead under the category of substitutions, to be discussed subsequently. Repetitions and false starts on the part of the $T$ are not considered additions to the text. Four types of events constituting additions may be specified :

a) $A 1$ : qualifier addition - addition of a qualifier or a qualifying phrase not in the original version.

E.g. $\mathrm{S}$ version : ... ils gardaient tous deux enracinés en eux ...

$\mathrm{T}$ version : ... they both had deeply rooted within themselves ...

Here the $T$, possibly for emphasis, has added a qualifier not in the original text.

b) $A 2$ : elaboration addition - addition in the form of an elaboration or other straight addition to the text.

E.g.1 $\mathrm{S}$ version : ... je dois rester conscient de ce qui est juste ...

$\mathrm{T}$ version : ... I must be aware and conscious of what is just and fair ...

E.g.2 $\mathrm{S}$ version : ... he'll major in medicine, in pre-med, ...

$\mathrm{T}$ version : ... en se spécialisant ... au cours prémédical, c'est-à-dire le ... MPC ...

In these examples the $T$ further elaborates what the $S$ is saying. In the second example the elaboration consists of quite extraneous - though helpful - material, the $T$ making reference to a specific program of studies (mathematics, physics, chemistry) directed at pre-medical students in France. Additions of types $A I$ and $A 2$ refer essentially to the same sort of event and could in fact be combined, though they have not been in the study.

c) $A 3$ : relationship addition - addition of a connective or of other material which results in a relationship of elements or of sentences not present in the original. 
E.g. S version : ... J'ai beaucoup apprécié aussi l'interprétation du film. Les deux grandes vedettes étaient ...

$\mathrm{T}$ version : ... I also enjoyed very much the performance of the actors ... because the two stars were ...

Here the $\mathbf{T}$ is introducing a causal relationship not explicitly stated in the original. This type of addition is somewhat more «serious » than the previous ones since it introduces some new meaning or relationship to what is being said, even if the gist is retained, whereas types $A 1$ and $A 2$ elaborate what is being said without altering the meaning.

d) $A 4$ : closure addition - addition which accompanies rephrasing, omission or misinterpretation on the part of the $T$ and which serves to give \& closure » to a sentence unit, but does not add anything substantial to the sentence.

E.g.1 $\mathrm{S}$ version : ... et leur tour de poitrine augmente plus rapidement que leur tour de tête ...

$\mathrm{T}$ version : ... and their chest measurement also increases ...

Here the $T$ has missed part of the original, and to give closure to his sentence he adds the word « also ».

E.g.2 $\mathrm{S}$ version : ... des messieurs qui décident ... du choix des livres qu'ils vont publier et de la façon dont ils vont le faire ...

T version : ... men who decide ... the selection of the books which are going to be published and how they're going to be offered to the public ...

Here, although the gist of what is said is retained, it is surmised that the $T$ has misinterpreted some of the text, since a more straightforward translation of la façon dont ils vont le faire would be «the way in which they are going to do it », without any mention of « offering » or of «the public». We assume that the $\mathrm{T}$ misunderstood something relating to offert in the place of le faire, resulting in his version : "now they're going to be offered... ». To give closure to the sentence, the phrase «to the public», which is clearly extraneous to the text, is added. The part which is added is of little consequence, but this is not the case for the part which is misunderstood or substituted, which represents a more serious departure.

In addition to the above, a few other types of additions were noted which, however, were not included in the final coding scheme since they were judged inconsequential and, in most cases, too few in number. They may be described as follow : $i$ ) addition of connective « and ( or French et) between phrases or sentences, resulting in a linking of separate units. This was a fairly common addition with some Ts for certain passages; ii) addition of specification, substituting « this/that » for « the » or some similar event, or specifying an item referred to pronominally in the original; iii) translation of language-specific items not required in the target language, as when the definite article is carried over from French into English : e.g., «the President Kennedy»; iv) addition of preposition or other item resulting in an ungrammatical structure, but not contributing to or affecting the meaning of the material; $v$ ) addition on the part of the $T$ of extraneous material or comment not related to the text. This is restricted to " amateur» Ts (persons fluently bilingual but with no training in interpretation) who occasionally, for example, «filled » a missed item by saying « the... (blank) » or «the... (something) » in the place of the item, and who at times added remarks indicative of slight annoyance, to say the least ! 
3. Substitutions and errors - This category refers to material which is substituted by the $\mathrm{T}$ for something said by the $\mathrm{S}$. The substitution may involve a single word, or it may involve a whole clause; and whereas some substitutions hardly affect the meaning of what is being said, others alter it considerably and represent more serious « errors» of translation. A substitution necessarily represents a combination of omission and addition, but is considered as a category independently of these events. Five types of substitutions (errors) have been specified, some involving subcategories :

a) E1 : mild semantic error - error or inaccuracy of translation of some lexical item, which only slightly distorts the intended meaning. Such errors may be associated with an awkward translation. The inaccuracy is restricted to the lexical item or expression, and does not affect the rest of the unit of which it is part.

E.g. $\mathrm{S}$ version : ... il n'a jamais montré de malveillance ni de méchanceté ...

$\mathrm{T}$ version : ... he never showed an evil mind or an evil reaction ...

Here the T's version is slightly awkward and inaccurate, but the gist of what is said is fairly well retained.

b) E2 : gross semantic error - error of translation of some lexical item which substantially changes the meaning of what is said. Here again, the error is primarily in terms of a specific item and does not affect the rest of the unit. There are three types of events falling in this category :

i) E2a : error stemming from assumed misunderstanding by $\mathrm{T}$ of some lexical item because of a homonym or near-homonym, or because of confusion in reporting with a near-sounding word.

E.g.1 S version : ... l'autocritique est l'arme secrète de la démocratie ...

T version : ... (seif-criticism is) the secret soul (of democracy) ...

Here the $\mathrm{T}$ apparently misunderstood l'âme for l'arme, resulting in his translation.

E.g.2 $\mathrm{S}$ version : ... la diplomatie parlementaire ...

$\mathrm{T}$ version : ... parliamentary democracy ...

Here it is assumed that in listening or in reporting, the $\mathrm{T}$ confused the two words « diplomacy» and « democracy».

ii) $E 2 b$ : error of false reference, possibly stemming from confusion and having its basis in the text (and thus differing from the error of "confused reporting 》 of type $E 2 a$, which brings an element extraneous to the text).

E.g.1 $\mathrm{S}$ version :... nous savons qu'il avait foi ...

$\mathrm{T}$ version :.... we know that we had faith ...

Here it may be that the $\mathrm{T}$ has confused the subject of the subordinate clause with that of the principal clause, leading to an error of «false reference».

E.g.2 $\mathrm{S}$ version : ... ce qui n'empêche pas les enfants de la ṇouvelle génération d'être plus grands que leurs pa:ents ...

T version : ... which doesn't prevent children ... from being taller than their children ...

Such errors are possibly less damaging than those falling under E2a, since the listener probably realizes that the $T$ has made a mistake of reference and can « correct » it, but this may be more difficult to do in the case of errors of type $E 2 a$.

Under this category are also included a few instances of displaced reference :

E.g.3 $\mathrm{S}$ version : ... I believe it was anyway - this is the comment made in Time magazine ... $\mathrm{T}$ version : ... je crois qu'il s'agissait - en tout cas, c'est ce que disait Time magazine ... 
Here, in the original version, " anyway » refers to «I believe it was 》, as can be determined from $S$ 's delivery. The $\mathrm{T}$ has displaced it and incorporated it into the following unit, to give « anyway, that is what Time magazine said ».

iii) $E 2 c$ : error of meaning, not due to confusion :

E.g. S version : ... et [il] se demande, avec quelque angoisse ...

$\mathrm{T}$ version : ... and he looks, with some anxiety ...

Here it is judged that the translation of se demande as «looks » constitutes a substantial semantic error, which does not seem to be due to confusion with another word in the text.

Also included here are errors which appear to have no basis in the text and for which no suitable explanation can be found :

E.g. $S$ version : ... je n'ai jamais admiré ni aimé personne plus que lui ...

$T$ version : ... I have never forgotten or liked anyone else as much as $I$ did like and admired him ...

Why the $\mathrm{T}$ initially translated admiré as «forgotten 》 is not known; it seems unlikely that admiré could be misunderstood as oublié. The $\mathrm{T}$ did in fact hear admiré since it enters into is translation, and it may simply be that $\mathrm{T}$ anticipated that $S$ would say je n'ai jamais oublié. Such instances were very rare.

In addition, this category contains instances of clearly unintelligible material :

E.g. $S$ version : ... in the actual presentation ...

$\mathrm{T}$ version : ... dans la présentation dockswall (?) ...

It may be surmised that the unintelligible word «dockswall» (?) is an approximation of the word « actual » or actuelle, but it defies comprehension.

There are thus two categories for semantic errors, one referring to mild errors or substitutions which more or less retain the meaning intended by the $S$, the other referring to more serious errors, with substantial change of meaning. Although three subcategories are specified in the latter case, they may be combined into one class of « gross » semantic errors.

The remaining categories of errors or substitutions refer to departures of the translation from the original which involve a whole phrase or unit, rather than a single lexical item. Three such categories have been specified, although here again they represent differing degrees of departure rather than distinctive categories.

c) E3 : mild phrasing change, where the $\mathrm{T}$ does not say quite the same thing as the $\mathbf{S}$, but the gist of what is said is not affected.

E.g.1 $\mathrm{S}$ version : ... il aurait fort bien pu reprendre à son compte les paroles de Shakespeare ...

$\mathrm{T}$ version : ... we could very well say about him the words of Shakespeare ...

Here the $T$ makes a change in the subject of the sentence and changes the phrasing slightly, but the gist of what is said by $S$ is retained.

E.g.2 S version : ... dans ce Conseil qu'il a si fortement marqué de sa personnalité ...

$\mathrm{T}$ version : ... in this Council to which he gave so much of his personality ...

These phrasing changes are very mild and are generally acceptable within the context of simultaneous interpretation, where the $T$ is allowed a certain latitude in his wording.

d) E4 : substantial phrasing change - Here, the change in phrasing is more 
marked and leads to a difference in meaning, but the overall gist of what is said by the $\mathrm{S}$ is not too distorted.

E.g. $S$ version : ... je trouve que ce film est une réussite, une manière de réussite ...

$\mathrm{T}$ version : ... I would like to say that this is an excellent film, that it was a great success ...

As can be seen, the $T$ has substantially rephrased what the $S$ was saying, but the gist of the message is not too distorted.

Not all instances coded in this category were as substantial as the above example. There were in fact two subcategories, which were eventually combined. The phrasing changes considered in this category are more marked than those in $E 3$, but less serious than those in the following category.

e) E5 : gross phrasing change, resulting in a considerable difference in meaning. In this category are included all gross departures in meaning, which can arise on the basis of several factors. Among such causes were noted the following : i) error of mistranslation :

E.g. S version : ... qui occupent dans cette maison un emploi salarié ...

T version : ... (who) ... are even paid by this publisher ...

ii) the $\mathrm{T}$ seems to « make up » something on the basis of some part of the text. This may be due to his lack of comprehension of what is said, or because of his lagging too far behind the $\mathrm{S}$, which prevents him from fully understanding what $S$ has said, and he consequently tries to "fib» his way through the text on the basis of some word in it.

E.g. $\mathrm{S}$ version : ... je dois garder enracinés en moi certains principes ...

T version : ... (substantial delay) ... and there are certain roots to this ...

iii) different meaning resulting from omission of some item :

E.g. $\mathrm{S}$ version : ... il a eu ... de grandes déceptions, et il $y$ a été sensible.

$\mathrm{T}$ version : ... he had great disappointments, and he was sensitive.

$i v)$ error due to misunderstanding of some item :

E.g. S version : ... (des écrivains qui) ... n’y occupent aucun autre emploi sinon celui de lecteur ...

T version : ... they have another job which is that of a reader ...

Here the $T$ appears to have misunderstood un autre for aucun autre, resulting in a meaning almost opposite to what the $\mathrm{S}$ said. This type of error is similar to error $E 2 a$, but it affects the meaning of a whole unit rather than just the word involved.

Other events were also classified in category E5 : meaningless or confused translations, reversals of meanings, transforming a question into a statement, etc. Some instances of confused translation were classified in either category E4 or E5 depending upon their seriousness. These various events were initially coded separately, but were subsequently incorporated into one or an other of the phrasing changes categories. Essentially, we established three levels of phrasing changes or errors, exemplified by categories $E 3, E 4$ and $E 5$, and we determined which was the more appropriate in any one instance.

The above description summarizes the main types of departures of the interpretation from the original noted in the course of the study, although we have by no means exemplified all the different variations of events associated with each category. The coding system had to be restricted, so that events differing in some 
respects have been included in the same category, but the main classifications reflect different \& types » of departures. As stated earlier, the system has obviously involved a good deal of subjectivity on the part of the coder, both in terms of the categories delineated and in the assignment of events to these categories, but this cannot be avoided when the basic dimension involved is that of meaning or meaning equivalence. The coding system is only meant to be an attempt at some systematization in the consideration of departures of translation occurring in simultaneous interpretation, and can no doubt be improved. Nor is the system intended to reflect except in a very gross way on the adequacy or " quality » of an interpretation since other critical factors such as delivery characteristics : voice intonation, appropriateness of pausing, etc., are not taken into consideration.

\section{SOME RELEVANT DATA}

We shall only very briefly comment on some findings of the investigation relating to departures of interpretation, since a detailed discussion of the data is beyond the scope of the present paper.

As stated earlier, six Ts were tested in the study : two fully qualified professional Ts, two «student» Ts who had recently completed an approved program in interpretation, and two «amateur» Ts who, as previously mentioned, were persons fluently bilingual in French and English but with no experience in simultaneous interpretation. These amateurs, however, had an active interest in languages, being affiliated with the language department of a university. (This may account in some measure for their, in fact, rather good performance in view of their total inexperience, though their performance would of course still be judged quite poor by professional standards.) In each category of Ts one was Englishdominant and the other French-dominant, the alternate language constituting in all cases the «weaker» language of the $T$. The Ts were required to translate five passages from their weaker into their dominant language and three passages from their dominant into their weaker language.

Looking first at omissions, two basic measures may be considered : the number of instances of omissions and the amount of material omitted. Since the various texts used in the study differed in length, the number of instances of omissions had to be standardized to a common text length, which was selected as 100 words (of original text), not counting words associated with repetitions, false starts, etc. Of the six Ts tested in the study, three could be classified as « morequalified Ts (the two professional Ts and one of the student Ts) and three as "less-qualified Ts» (the two amateurs and the other student $T$, whose performance, in comparison with that of the more-qualified Ts, was rather poor). The more-qualified Ts make on the average from 2 to 4 omissions per 100 words and omit from 5 to $10 \%$ of the material, while less-qualified Ts make in the neighbourhood of 6 omissions per 100 words and omit from 20 to $25 \%$ of the material. These figures, of course, vary from text to text, and it is found that the measures of omission vary directly with rates of "input " - the proportion of speech associated with the message, i.e. the extent to which the $S$ is actually engaged in speaking in the course of his delivery (he may, for example, be actually 
speaking during $60 \%$ of the time that it takes him to deliver his message, while the other $40 \%$ is associated with halts and pauses in his delivery), and the speech rate of the $\mathrm{S}$, i.e. the number of words or syllables that he utters in a fixed period of time. These findings offer support for the intuitively reasonable assumption that the more the $S$ speaks in a fixed period of time, the more often and the greater the amount of material likely to be omitted by the $T$.

Although the difference in the number of omissions associated with morequalified and less-qualified Ts does not at first glance seem particularly striking (though it must be remembered that the measures are based on only 100 words of text, so that a difference of 2 to 4 omissions per 100 words does «add up » over an extended text), the two groups differ in the degree of «seriousness 》 of the omissions : whereas about $80 \%$ of the omissions of the more-qualified Ts are of the minor «skipping » variety (type $M I$ ) and thus only about $20 \%$ are more «serious », for less-qualified Ts roughly half or $50 \%$ of their omissions fall in the latter category. Whereas more-qualified Ts have about the same omission measures associated with interpretation in either direction (from their weaker into their dominant language or vice versa), less-qualified Ts, interestingly, usually do «better » when translating from their dominant into their weaker language, making fewer omissions and omitting less material in that situation than when translating from their weaker into their dominant language, which is the more «natural» direction.

Turning to «additions 》 of interpretation, two indices can likewise be calculated : the number of additions, which in this case is calculated on the basis of the amount of original material effectively translated (i.e. excluding material omitted by the $\mathrm{T}$ ), and the proportion of the translation (in terms of number of words) which constitutes added material (excluding words relating to repetitions, false starts, etc.). It may be said that in general there is very little addition of material in interpretation, some Ts making almost no additions, others making at the most 2 to 3 additions per 100 words (of original material effectively translated), and added material accounting for only 1 to $5 \%$ of the T's verbal output. Most additions are of the «qualifier» and «elaboration» types ( $A 1$ and $A 2$ ). There is a tendency for fewer additions to occur in relation to prepared texts (such as in the translation of a text initially intended for the written medium) than in relation to less structured passages. This may reflect the degree of formalism associated with such material, which may call forth a more rigid and set translation, whereas texts intended for oral delivery allow the $T$ greater freedom of idiom, with a greater possibility of additions. With regard to the proficiency level of the $\mathrm{T}$, there is possibly a tendency on the part of morequalified or professional Ts to add more material than less-qualified Ts; this may be attributable to their very expertise, which frees them from following the text too closely, in an almost literal fashion as is the case with amateurs, and hence increases the likelihood of slight changes and additions. Adding material in translation, it is evident, is not as «serious 》 an offense as omitting material or mistranslating part of the text, unless of course the added material is inappropriate to the context or leads to misinformation. 
In considering substitutions and errors of translation, the number of errors must also be calculated on the basis of the amount of original material (number of words) effectively translated, i.e., removing from the word total words associated with omitted material, since for such material the possibility of concomitant errors is effectively removed. Due to a number of considerations, a measure relating to the amount of material associated with errors is not as readily calculable and is not in any case as pertinent as the number of instances of errors. More-qualified Ts make in the neighbourhood of 3 errors per 100 words (of translated material) while less-qualified Ts make about 4 errors per 100 words (this figure is the result of an anomalously low error index for one of these Ts), but there are individual variations, and for some texts, embarrassingly enough, some less-qualified Ts make fewer errors than some more-qualified Ts. This finding is not really as disconcerting as it may appear at first : since less-qualified Ts omit considerably more material than more-qualified $\mathrm{Ts}$, they effectively have fewer possibilities of making errors since the error index is based on the amount of effectively translated material. It must also be recognized that the coding system probably favours the less-qualified $\mathrm{T}$ while penalizing the morequalified $\mathrm{T}$ to some extent because of his very expertness. In coding errors, the main concern is with the «fidelity » of the translation, the issue being whether the meaning of what is said in the original text is conveyed by the $\mathrm{T}$ in translation, and not so much with how elegantly it is conveyed. A distinguishing characteristic between more-qualified and less-qualified Ts is the degree of literalness of their interpretations : those by amateur Ts are typically very literal, being in many instances almost word-for-word «verbal transpositions » rather than translations, whereas those by professional Ts are substantially more in agreement with the idiom of the target language. Translations by amateurs are thus considerably more «awkward» and less intelligible or comprehensible than those of morequalified Ts. The coding system, however, does not reflect too much on the overall intelligibility of the translation; its primary concern is with changes in meaning. Since professional Ts make an attempt at idiomatic expression, greater opportunity arises in their case for slight phrasing changes to occur than is the case with less-qualified Ts. The data in fact generally indicate proportionally fewer «minor» errors (types E1 and E3) for amateur Ts than for more-qualified interpreters.

Since the error index is not independent of the measure of omission and since both omissions and errors are disruptive of translation, these two categories of events can be combined to yield a general index of translation disruption. When this is done, the emerging pattern is quite consistent with expectations in establishing the superiority of the more-qualified Ts. Again, less-qualified Ts are characterized by generally better performance when translating from their dominant into their weaker language, showing on the average fewer disruptions - and fewer « serious» ones (omission types $M 2$ and $M 3$ plus error types $E 2$, $E 4$ and $E 5$ ) - in that direction than when translating from their weaker into their dominant language. (Their translations, however, are to some extent even more literal when translating from dominant into weaker language.) 
The above remarks constitute only a very brief description of some of the findings of the investigation relating to departures of interpretation. The data presented above should not be taken too «literally». If the performance of lessqualified Ts does not appear that strikingly different from that of more experienced interpreters on the basis of the few measures reported here (though, as previously stated, the fact that the measures are based on a very restricted text length 100 words - masks the overall difference in relation to the actual text lengths), it must again be repeated that the indices developed do not give the "whole picture ». They are meant only to quantify in a very general way the extent of departure between original and interpreted version, but do not reflect on other critical dimensions such as overall comprehensibility of the interpretation, degree of idiomaticalness, clarity of diction, etc., which are of obvious significance in simultaneous interpretation. Much work remains to be done in the area.

\section{APPENDIX}

Example of application of coding system - (Omissions are reported on the $\mathrm{S}$ transcript, additions on the $T$ transcript, and errors on both transcripts in sequential correspondence - the first error on the $S$ transcript corresponding to the first error on the $T$ transcript, etc.) :

$\mathrm{S}$ version : J'étais à Londres mercredi soir lorsque la nouvelle s'est répandue dans $\underset{\mathrm{M}-4}{\mathrm{M}-4}$ les rues
$\mathrm{E}-5$ pleines de monde que (Monsieur X) était mort. Quand nous avons pu enfin y croire, nous avons

ressenti tous comme un choc, une grande tristesse, un sentiment de deuil. Nous connaissions en lui un grand Américain, mais, comme le Président Kennedy, nous sentions qu'il était à nous tous. J'ai ressenti moi-même une grande désolation, car je cont E-3 E-3 M-3

(Monsieur $\mathrm{X}$ ), depuis l'époque où il avait coutume de venir nous voir, il y a des années, à la Jamaïque. Je n'ai jamais admiré ni aimé personne plus que lui.

${ }_{\mathrm{M}-2}$

T version : Wednesday evening the news spread throughout the world that (Mister $\mathrm{X}$ ) was

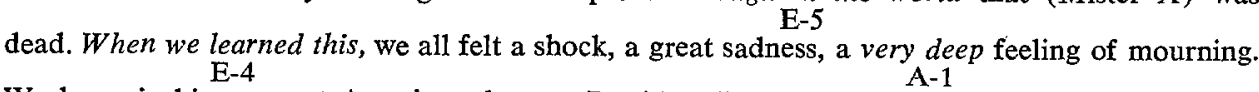
We knew in him a great American, but, as President Kennedy, we felt that he was one of us. I knew for a long time and very well (Mister X), since the time when years ago ... I have never ...

HENRI C. BARIK 